\title{
Clinical laboratory findings in the elderly
}

\author{
O laboratório clínico na terceira idade
}

Primeira submissão em 13/07/11 Última submissão em 13/07/11 Aceito para publicação em 24/03/12 Publicado em 20/06/12

Alvaro Pulchinelli Junior'; Abrão José Cury Jr.; ; Antônio Cantero Gimenes ${ }^{3}$

\begin{tabular}{l|l}
\multicolumn{1}{c|}{ key words } & abstract \\
Clinical laboratory & $\begin{array}{l}\text { The aging of Brazilian population is inevitable. Thus, this article reviews the main aspects related to } \\
\text { the elderly population, taking into account the particularities and problems encountered in the clinical } \\
\text { laboratory when serving this population group. We start with a brief review of the aging process } \\
\text { physiology and then discuss the difficulties of pre-analytical (appropriateness of care), analytical (main } \\
\text { issues for this age group sorted into body system categories) and post-analytical phases. }\end{array}$ \\
Geriatrics & $\begin{array}{l}\text { Physiology of aging } \\
\text { isten }\end{array}$
\end{tabular}

resumo

O aumento da população idosa em nosso meio é fato incontestável. Assim, este artigo faz uma revisão dos principais aspectos referentes a essa população, sempre considerando as particularidades e os problemas observados no atendimento dessa faixa de população no laboratório clínico. Partimos de uma breve revisão sobre a fisiologia do envelhecimento para então percorrermos as dificuldades das fases pré-analítica (adequação do atendimento), analítica (principais problemas dessa faixa etária, divididos por sistemas orgânicos) e pós-analítica. unitermos

Laboratório clínico

Terceira idade

Geriatria

Fisiologia do

envelhecimento

1. Doutor em Ciências; patologista clínico da Escola Paulista de Medicina da Universidade Federal de São Paulo (EPM/UNIFESP) - Centro Alfa; médico da Cestão da Saúde do Crupo Fleury.

2. Mestre em Ciências; médico clínico da EPM/UNIFESP - Centro Alfa.

3. Especialista em Clínica Médica e Cardiologia; cardiologista do Hospital do Coração, São Paulo. 


\section{Introduction}

The aging process, or senescence, used here as a synonym, is a topic that is not thoroughly understood. Experimental studies using humans are subject to restrictions, and the literature offers models based on rodents and other organisms, such as the nematode Caenorhabditis elegans, the fruit fly Drosophila melanogaster, and the yeast Saccharomyces cerevisiae, whose biological characteristics, such as a short life span, a broadly sequenced genome, and a well-characterized biology, facilitate scientific research.

\section{Biological aspects of aging}

There are proposed theories to explain the aging process, and here we provide a brief discussion of each as well as a description of the expected changes in some organs. There are three proposed theories: evolutionary, molecular-cellular (cellular senescence), and systemic.

\section{Evolutionary theory}

Evolutionary theory presents several interesting facets, such as the low prevalence of death in early adulthood and the increasing prevalence in late adulthood. The maturity of reproductive function marks the beginning of aging, and the earlier the onset of reproductive capacity, the earlier the onset of the aging process ${ }^{(22,24)}$.

\section{Cellular senescence}

Senescence can be expressed in two ways: stressinduced senescence resulting from molecular events and replicative senescence resulting from the loss of telomeres. Telomere shortening can be considered a molecular clock that signals replicative senescence.

Theories based on molecular and cellular mechanisms of aging are related to errors in protein synthesis that accumulate throughout life and mutations that arise due to exposure to the external environment, especially sublethal doses of radiation, which can induce changes that can promote death over the long term. The association with errors in DNA replication contributes to increasing the likelihood of this outcome ${ }^{(23)}$.

The presence of free radicals predicts that regulatory mechanisms of production will become ineffective with age, and the accumulation of superoxide causes structural damage to cells, causing irreparable damage.

\section{Systemic theory}

The nervous, endocrine and immune systems play an important role in controlling the body's responses to external and internal stimuli. A lack of control in the performance of these systems will accelerate the aging process( ${ }^{(2)}$.

From a neuroendocrine point of view, it is believed that aging results from changes that occur in the hypothalamicpituitary-adrenal systems, which act as regulators. Changes that compromise the function of this axis, such as a low response to stimulation, contribute to an accelerated aging process.

Immunological changes are based on two premises: the decline of the functional capacity of the immune system and increased production of auto-antibodies. Immune senescence is thus characterized by reduced resistance to infections, the rise of neoplasia, and a reduction of the capacity for auto-recognition, which facilitates the occurrence of autoimmune diseases.

\section{Cardiovascular system}

Cardiac structural changes are marked by increased myocardial thickness, deposition of collagen tissue, and increased heart stiffness. Changes in arterial cell and renal perfusion are also identified. Coronary heart disease in elderly patients is two to three times higher than in patients younger than $65^{(5)}$.

\section{Respiratory system}

Conformational changes of the nose and of the costal cartilage, costo-vertebral joints, and lungs determine the senescence process characteristic of elderly patients. The main functional changes in the respiratory tract in elderly are:

- reduction of the chest wall;

- reduction of respiratory muscle strength;

- reduction of vital capacity;

- increased residual volume;

- increased arterial-alveolar oxygen gradient;

- reduction of pulmonary diffusion;

- hypoxia;

- hypercapnia.

\section{Renal system}

Renal blood flow tends to decrease by $50 \%$ due to a progressively decreasing rate of glomerular filtration. 
Comorbidities, such as hypertension, diabetes, and previous episodes of pyelonephritis, may further influence the effects of senescence.

\section{Nutritional and metabolic factors}

There is a decrease in basal metabolism, a redistribution of body mass, and change in the digestive system. With increasing age, there is an increase in body fat and abdominal fat internalization. These phenomena are present in both males and females ${ }^{(19)}$.

As a result of obesity, diseases, such as hypertension and diabetes, increase in prevalence. An important metabolic factor is the occurrence of hyperelectrolytic disturbances, such as hyper- or hypo-natremia, which, when associated with other comorbidities, are associated with worse mortality and morbidity ${ }^{(10)}$.

\section{Laboratory aspects}

\section{Pre-analytical factors}

When a patient in this age group seeks health services, the first concern will be how to welcome the patient. Clinicians should also treat the physical facilities involved as a primary concern. Each unit should be equipped with devices that provide ease and comfort, ensuring the safety of the patients. It is important to remember that in this age group, difficulties with mobility, hearing, and vision are not uncommon. Clinics should be designed with these possible limitations in mind. The accessibility of the units should be developed to the fullest. Handrails and grips at appropriate heights should be available in corridors, collection rooms, and bathrooms. Furthermore, toilet bowls should be set at appropriate heights, and security handles should be provided.

The floor should be as uniform as possible, with ample provision of ramps and non-slip flooring, avoiding stairs and slopes.

The visual and auditory signals must be clear and prominent. Protocols should use large letters for easy viewing.

The process of sample collection should go beyond a collector well trained in the collection technique. A tourniquet should be applied to the minimum degree necessary, and extended use should be avoided. When a tourniquet is applied for more than three minutes, it can raise cholesterol by $5 \%$ and aspartat aminotranferase (AST) by almost $10 \%$.
It is important to remember that patients of this age have to be treated with respect and care but not as children. Calmness and patience in this type of care are essential.

The clinical status of these patients may be extremely variable. Their state depends not only on the coexistence of multiple diseases, but also on aspects related to treatment of the patients past medical problems and to how the patient has been followed. Therefore, trying to set standards in terms of benchmarks and their consequences, such as communication or panic levels, becomes a complicated task.

These patients also present with polypharmacy. Drugs can interact with each other not only in vivo, but also in vitro. Insisting on obtaining information about the current drugs being used can solve many problems related to treatment

Variations in clinical status are also affected by genetic factors and aspects of body composition. We know, for example, that levels of creatine kinase (CK) enzyme are generally higher in populations of African descent because individuals in these populations have more muscle mass. By contrast, white women have lower muscle mass. Substances produced by the muscles (such as CK and creatinine) may change $\mathrm{e}^{(16)}$.

In turn, patients with a higher fat mass have increased levels of lipids, transaminases, insulin, glucose, and cortisol.

Menopause can alter the results of tests related to bone metabolism, and alkaline phosphatase may vary by up to $25 \%$.

In summary, changes that are frequent in the elderly, such as changes in body composition and height loss, lead to a new homeostatic balance, which can vary in comparison to young adults.

Environmental factors also influence these patients and the results of their laboratory tests. Inpatients hospitalized for long periods or under inappropriate conditions should be evaluated carefully. Patients exposed to constant cold may have increased thyroid-stimulating hormone (TSH) and decreased thyroxine hormone (T4). Constant stress can alter corticotropin-releasing hormone (CRH), aldosterone, and renin. Additionally, stress can also lower thyroid hormones (TSH, triiodothyronine [T3] , and T4).

In immobilized patients (forced postures), the plasma volume falls between $5 \%$ (on the first day) and $8 \%$ (on the sixth day). Calcium, urea, and T4 rise, while cortisol and metanephrine decrease.

Diet is also an important consideration because these patients often have chewing and swallowing problems and, therefore, opt for a diet with a higher proportion of 
carbohydrates and fats. Malnutrition is common, and one study showed that up to half of admitted patients have low transferrin. The state of hydration must also be taken into consideration, and adequate hydration should be ensured.

The circadian rhythm can also change, and sleep disturbances are common. Cortisol, aldosterone (which depends on movement), TSH, metanephrines, and peptide $\mathrm{C}$ may be altered in the elderly.

Even healthy habits can affect test results. Exercise, for example, leads to higher protein turnover and increases the levels of circulating enzymes and stress hormones (cortisol, metanephrines, aldosterone, B-type natriuretic peptide $[B N P])$. However, it reduces cholesterol and triglycerides.

\section{Changes in laboratory evaluation of physiological systems}

Some changes are more prevalent in this population, and we will briefly discuss the clinical-laboratory correlations.

\section{Endocrine changes}

The most relevant changes are thyroid and metabolic syndromes. Thyroid function remains stable, despite the decrease in T3 due to reduced peripheral conversion of T4 into T3. T4 remains stable because reduced synthesis is offset by lower clearance.

There is an increase in the peripheral resistance of these hormones, and this resistance explains the fact that the TSH remains within the reference range.

Thyroid disorders are also common in this population. Hypothyroidism appears in $4 \%$ of the population, and it is present in subclinical form in $5 \%{ }^{(4)}$. Approximately two thirds of the population in this age group tested positive for anti-thyroid antibodies ${ }^{(12,14)}$.

Hyperthyroidism also presents with vague symptoms, such as cardiac abnormalities (tachycardia, atrial fibrillation, angina, congestive heart failure [CHF]), neurological abnormalities (weakness, emotional disorders), and gastrointestinal abnormalities ${ }^{(15)}$.

Hypothyroidism can also be frustrating to identify because the symptoms are not always clear to the doctor. It can present as debility, cold intolerance, constipation, dry skin, mental confusion, chronic anemia, or other autoimmune manifestations. The aspect of confusion can be difficult to differentiate from symptoms of dementia. Dementia resulting from hypothyroidism has been shown to be an important cause of debility. Other serious illnesses can present similarly, and therefore, the laboratory plays an important role in diagnosis ${ }^{(12)}$.

Metabolic syndrome, which is well known in our country, should be considered based on the significant increase in its likelihood that is correlated with age ${ }^{(19)}$.

\section{Assessment of renal function}

Kidney function declines with age, falling about $1 \%$ per year. Renal plasma flow begins to decrease earlier than the glomerular filtration rate, which leads to a delay in clearance measures for assessing the extent of renal function ${ }^{(6)}$.

Creatinine remains stable because the production and excretion rates fall together, i.e., the loss of muscle mass (responsible for the production of creatinine) follows the reduction in excretion ${ }^{(1)}$. Three factors directly influence the plasma concentration of creatinine: muscle mass, age, and diet. We know that an overload of animal protein in the diet can raise the levels of serum creatinine from $10 \%$ to $20 \%$.

The route of excretion is glomerular filtration (for the greater part) and tubular secretion (for the lesser part). During renal insufficiency, tubular secretion becomes more significant, and purification may be overestimated by $50 \%$ to $200 \%$. Creatinine purification is not related linearly with serum levels, so it is always important to remember that relatively "small" changes may indicate large decreases in renal function ${ }^{(7)}$.

Collection of the sample itself can be performed over a period of 12 to 24 hours or over shorter periods. Certain precautions should be taken, such as ensuring the accuracy of timing during collection, starting the test with a proper emptying of the bladder, providing adequate hydration, and preventing the loss of urine. Ideal hydration should be initiated with $20 \mathrm{ml} / \mathrm{kg}$ of body weight plus replacement.

In elderly patients, complications related to each of the items mentioned may be present, including difficulty for understanding the instructions for the collection, incomplete bladder emptying (residual urine), water restriction for medical reasons, and inability to control and collect urine (patients with urinary incontinence, for example).

The formulas most commonly used for estimation (Cockcroft-Gault and Modification of Diet in Renal Diseases [MDRD]) can be used with good accuracy, but purification of less than $60 \mathrm{ml} / \mathrm{min}$ is not recommended ${ }^{(8)}$. The use of cystatin $\mathrm{C}$ may be considered ${ }^{(11)}$, although it is not yet in common use in our area. 


\section{Hematological features}

Hematological problems are common in the elderly(17). Bone marrow also undergoes characteristic changes over time. Values that would be considered appropriate in other age groups can take on a different clinical significance in the elderly ${ }^{(20)}$. Leukocyte counts of approximately $10,000 / \mathrm{mm}^{3}$ may be normal for a youth, but in the elderly, this count may be highly indicative of infection ${ }^{(18)}$.

Anemia is a disease that is more prevalent in the elderly ${ }^{(9)}$. Its prevalence increases with age and other comorbidities. These include iron deficiency, chronic disease, bleeding, and injuries to the spinal cord $^{(3)}$ (myelodysplasia and myeloproliferative disorders). A suggested strategy is to administer ferritin to differentiate between anemia caused by iron deficiency and that caused by chronic disease.

Lymphomas and myelomas are also important manifestations in this age group because their clinical manifestations are different from those observed in young adults $^{(25)}$. Anemia is a disease that is more prevalent in the elderly. Its prevalence increases with age and other comorbidities. These include deficiency, chronic disease, bleeding and injuries to the spinal cord (myelodysplasia and myeloproliferative disorders).

\section{Markers of inflammatory activity}

Inflammatory diseases are a common problem in older people. Thus, the evaluation of markers of these diseases involves some care regarding the interpretation of results ${ }^{(13)}$.

The tests are nonspecific, with high sensitivity, low specificity, low positive predictive value (PPV) and high negative predictive value (NPV). Therefore, negative results should be evaluated, and positive results should be carefully analyzed.

Common exams in clinical practice, such as antinuclear factor and thyroid antibody tests, also deserve attention. In an important study, Tan et al. showed that up to $3 \%$ of the population may have false-positives in high titers ${ }^{(21)}$.
Anti-thyroid antibodies, as well as other auto-antibodies, have an elevated incidence with increasing age.

\section{Monitoring of therapeutic drugs}

High or low values can be found in this range. Difficulty of absorption due to reductions in motility and the absorptive surface and differences in tissue distribution, with more body fat and less tissue perfusion, are factors involved in therapeutic drug levels. Additionally, metabolism is slower and excretion is impaired by reduced kidney and/or liver function ${ }^{(18,26)}$.

\section{Conclusion}

Increases in the elderly population, especially those considered very old (over the age of eighty years), make it necessary to study this age group not only from the standpoint of institutional policies but also to address the various clinical and physiological factors that they are subject to.

It falls to the physician, regardless of specialty, to take into account that the diagnosis or treatment of elderly patients always depends on careful analysis of the disease and the physiological changes associated with age. No less important are aspects related to quality of life, such as functional changes, which are studied by evaluating the normal and instrumental activities of daily living. Finally, these patients also often suffer from co-morbidity caused by a combination of diseases.

As noted above, the physiological changes caused by aging interfere significantly with the function of organs and systems, which is reflected in the results obtained in laboratory tests. Thus, the correct interpretation of these tests depends, more directly than in young adults, on the analysis of the clinical, functional, and social characteristics of each patient.

\section{References}

1. BROSNAHAM, G.; FRAER, M. Chronic kidney disease: whom to screen and how to treat, part 1: definition, epidemiology, and laboratory testing. South Med J, v. 103 , n. 2, p. 140-6, 2010 Feb.

2. CARDOSO, A. F. Particularities of the elderly: a review of the physiology of aging. Revista Digital, Buenos Aires, year 13, n. 130, 2009 Mar. Available at: <http://www.efdeportes. com/efd130/idosos-uma-revisao-sobre-a-fisiologia-doenvelhecimento.htm>. Access in: 2011 Oct. 6.

3. FADERL, S.; KANTARIJAN, H. M. Novel therapies for myelodysplastic syndromes. Cancer, v. 101, n. 2, p. 226-41, 2004 Jul. 
4. FATOURECHI, V. Subclinical thyroid disease. Mayo Clin Proc, v. 76, n. 4, p. 413-6; Quiz 416-7, 2001 Apr.

5. GENSINI, G. F.; CORRADI, F. Hypertension as a function of age. Ital Heart J, v. 1, suppl 2, p. 23-31, 2000 Jun.

6. HALLAN, S. I.; STEVENS, P. Screening for chronic kidney disease: which strategy? J Nephro, v. 23, n. 2, p. 14755, 2010 Mar-Apr.

7. JASSAL, S. V. Clinical presentation of renal failure in the aged: chronic renal failure. Clin Geriatr Med, v. 25, n. 3, p. 359-72, 2009 Aug.

8. JOHNSON, D.; USHERWOOD, T. Automated reporting of GFR: coming soon to a laboratory near you! Aust Fam Physician, v. 34, n. 11, p. 925-31, 2005 Nov.

9. JOOSTEN, E. Strategies for the laboratory diagnosis of some common causes of anaemia in elderly patients. Gerontology, v. 50, n. 2, p. 49-56, 2004 Mar-Apr.

10. KUGLER, J. P.; HUSTEAD, T. Hyponatremia and hypernatremia in the elderly. Am Fam Physician, v. 61, n. 12, p. 3623-30, 2000 Jun.

11. LAMB, E. J.; ORIORDAN, S. E.; DELANEY, M. P. Kidney function in older people: pathology, assessment and management. Clin Chim Acta, v. 334, n. 1-2, p. 2540, 2003 Aug.

12. LAURBERG, P. et al. Hypothyroidism in the elderly: pathophysiology, diagnosis and treatment. Drugs Aging, v. 22, n. 1, p. 23-38, 2005.

13. MISHRA, N.; KAMMER, G. M. Clinical expression of autoimmune diseases in older adults. Clin Geriatr Med, v. 14, n. 3, p. 515-42, 1998 Aug.

14.- MOKSHAGUNDAM, S.; BARZEL, U. S. Thyroid disease in the elderly. J Am Geriatr Soc, v. 41, n. 12, p. 13619, 1993 Dec.

15. MOORADIAN, A. D. Asymptomatic hyperthyroidism in older adults: is it a distinct clinical and laboratory entity? Drugs Aging, v. 25, n. 5, p. 371-80, 2008.
16. NARAYANAN, S. The preanalytic phase. An important component of laboratory medicine. Am J Clin Pathol, v. 113, n. 3, p. 429-52, 2000 Mar.

17. REMPHER, K. J.; LITTLE, J. Assessment of red blood cell and coagulation laboratory data. AACN Clin Issues, v. 15, n. 4, p. 622-37; Quiz 644-5, 2004 Oct-Dec.

18. RUSSO, M.; IASIMONE, L.; AMBROSINO, E. Antibiotic therapy in the elderly: features and problems. Infez Med, v. 10, n. 4, p. 204-12, 2002 Dec.

19. SOUZA, F. R.; SCHROEDER, P. O.; LIBERALI, R. Obesity and aging. RBONE, São Paulo, v. 1, n. 2, p. 24-35, 2007 Mar/Abr.

20. TAKUBO, T.; TATSUMI, N. Reference values for hematologic laboratory tests and hematologic disorders in the aged. Rinsho Byori, v. 48, n. 3, p. 207-16, 2000 Mar.

21. TAN, E. M. et al. Range of antinuclear antibodies in "healthy" individuals. Arthritis Rheum, v. 40, n. 9, p. 1601-11, 1997 Sep.

22. TEIXEIRA, I. N. D. O.; GUARIENTO, M. E. The biology of aging: theories, mechanisms, and perspectives. Ciênc Saúde Coletiva, v. 15, n. 6, p. 2845-57, 2010.

23. WARNER, H.; HODES, R.; POCINKI, K. What does cell death have to do with aging? J Am Geriatr Soc, v. 45, p. 1140-6, 1997.

24. WEINERT, B. T.; TIMIRAS, P. S. Physiology of aging. Invited review: theories of aging. J App/ Physiol, v. 95, p. 1706-16, 2003.

25. WESTIN, E. H.; LONGO, D. L. Lymphoma and myeloma in older patients. Semin Oncol, v. 31, n. 2, p. 198-205, 2004 Apr.

26. WILDIERS, H. et al. Pharmacology of anticancer drugs in the elderly population. Clin Pharmacokinet, v. 42, n. 14 , p. 1213-42. 